\title{
The genome-scale metabolic model ilN800 of Saccharomyces cerevisiae and its validation: a scaffold to query lipid metabolism Intawat Nookaew ${ }^{1}$, Michael C Jewett ${ }^{5,6}$, Asawin Meechai ${ }^{1}$, Chinae Thammarongtham ${ }^{2}$, Kobkul Laoteng ${ }^{2}$, Supapon Cheevadhanarak ${ }^{3}$, Jens Nielsen*5,7 and Sakarindr Bhumiratana*1,2,4
}

Address: ${ }^{1}$ Department of Chemical Engineering, Faculty of Engineering, King Mongkut's University of Technology Thonburi, Bangkok 10140, Thailand, ${ }^{2}$ Biochemical Engineering and Pilot Plant Research and Development Unit, National Center for Genetic Engineering and Biotechnology (BIOTEC) at King Mongkut's University of Technology Thonburi, Bangkhuntien, Bangkok 10150, Thailand, ${ }^{3}$ School of Bioresources and Technology, King Mongkut's University of Technology Thonburi, Bangkok 10140, Thailand, ${ }^{4}$ National Science and Technology Development Agency, Ministry of Science and Technology, Thailand Science Park, Klong Luang, Pathumthani 12120, Thailand, ${ }^{5}$ Center for Microbial Biotechnology, Biocentrum, Technical University of Denmark, DK-2800 Kgs. Lyngby, Denmark, ${ }^{6}$ Department of Genetics, Harvard Medical School, Boston, MA 02115, USA and 7Department of Chemical and Biological Engineering, Chalmers University of Technology, SE-412 96 Gothenburg, Sweden

Email: Intawat Nookaew - intawat.in@gmail.com; Michael C Jewett - mcjewett@genetics.med.harvard.edu; Asawin Meechai - asawin.mee@kmutt.ac.th; Chinae Thammarongtham - chinae@biotec.or.th; Kobkul Laoteng - kobkul@biotec.or.th; Supapon Cheevadhanarak - supapon.che@kmutt.ac.th; Jens Nielsen* - nielsenj@chalmers.se ;

Sakarindr Bhumiratana* - sakarindr@exchange.nstda.or.th

* Corresponding authors

Published: 7 August 2008

BMC Systems Biology 2008, 2:71 doi:10.1 186/1752-0509-2-71
Received: 14 March 2008

Accepted: 7 August 2008

This article is available from: http://www.biomedcentral.com/I752-0509/2/7I

(c) 2008 Nookaew et al; licensee BioMed Central Ltd.

This is an Open Access article distributed under the terms of the Creative Commons Attribution License (http://creativecommons.org/licenses/by/2.0), which permits unrestricted use, distribution, and reproduction in any medium, provided the original work is properly cited.

\begin{abstract}
Background: Up to now, there have been three published versions of a yeast genome-scale metabolic model: iFF708, iND750 and iLL672. All three models, however, lack a detailed description of lipid metabolism and thus are unable to be used as integrated scaffolds for gaining insights into lipid metabolism from multilevel omic measurement technologies (e.g. genome-wide mRNA levels). To overcome this limitation, we reconstructed a new version of the Saccharomyces cerevisiae genome-scale model, ilN800 that includes a more rigorous and detailed description of lipid metabolism.
\end{abstract}

Results: The reconstructed metabolic model comprises 1446 reactions and 1013 metabolites. Beyond incorporating new reactions involved in lipid metabolism, we also present new biomass equations that improve the predictive power of flux balance analysis simulations. Predictions of both growth capability and large scale in silico single gene deletions by ilN800 were consistent with experimental data. In addition, ${ }^{13} \mathrm{C}$-labeling experiments validated the new biomass equations and calculated intracellular fluxes. To demonstrate the applicability of ilN800, we show that the model can be used as a scaffold to reveal the regulatory importance of lipid metabolism precursors and intermediates that would have been missed in previous models from transcriptome datasets.

Conclusion: Performing integrated analyses using ilN800 as a network scaffold is shown to be a valuable tool for elucidating the behavior of complex metabolic networks, particularly for identifying regulatory targets in lipid metabolism that can be used for industrial applications or for understanding lipid disease states. 


\section{Background}

The yeast Saccharomyces cerevisiae is widely used for production of many different commercial compounds such as food, feed, beverages and pharmaceuticals [1]. It also serves as a model eukaryotic organism and has been the subject of more than 40,000 research publications [2,3]. After the complete genome sequence for yeast was released in 1996 [4], about 4,600 ORFs were characterized [3] and yeast contains many genes with human homologs [2]. This has allowed for comparative functional genomics and comparative systems biology between yeast and human. Yeast, for example, has been used to understand the function of complex metabolic pathways that are related to the development of human diseases [5-7].

Several human diseases (e.g. cancer, atherosclerosis, Alzheimer's disease, and Parkinson's disease) are associated with disorders in lipid metabolism [8-10]. The emergence of lipidomics has allowed analysis of lipid metabolism at the systems level $[8,11]$. Lipidomics promises to make a significant impact in our understanding of lipid related disease development [12]. As with other high-throughput techniques, however, we hypothesize that one of the main challenges for utilization of lipidome data will be our ability to develop appropriate frameworks to integrate and map data for studying relations between lipid metabolism and other cellular networks.

Previous work has shown that genome-scale metabolic models provide an excellent scaffold for integrating data into single, coherent models [13]. The calculation of Reporter Metabolites using genome-scale metabolic models is an example of how metabolic models can be used to upgrade the information content of omics data [14]. This approach allows mapping of key metabolites and reactions in large metabolic networks when combined with transcriptome [14] or metabolome data [15]. However, pathways, reactions, and genes that are not included in the metabolic network cannot be queried. Therefore, the Reporter Metabolite algorithm requires a reliable and global genome scale-model to achieve precise and accurate data interpretation.

So far, three yeast genome-scale metabolic models, iFF708, iND750 and iLL672, have been published. All three models, however, lack a detailed description of the lipid metabolism. The first model, iFF708 [16], consists of 1175 reactions linked to 708 ORFs. iFF708 shows good predictions of many different cellular functions [17] and gene essentiality predictions [18]. However, almost all intermediate reactions in lipid metabolism were either lumped or neglected. The second model published was iND750 [19]. iND750 is fully compartmentalized, consisting of 1498 reactions linked to 750 ORFs. The model was validated by a large-scale gene deletion study and metabolic phenotypes [20] and was expanded to include regulation for predicting gene expression and phenotypes of different transcription factor mutants [21]. iND750 contains more reactions and metabolites in lipid metabolism than $i F F 708$, but still lacks a comprehensive description of lipid metabolism. The third published model is iLL672, which is derived from iFF708 and comprises 1038 reactions. Several dead-end reactions of $i F F 708$ were eliminated leading to an improved accuracy of the single gene deletion prediction [22]. However, only minor improvements were made to reactions involved in lipid metabolism. The model was validated using ${ }^{13} \mathrm{C}$-labeling experiments to study the robustness of different yeast mutants [23].

Here our objective was to expand the genome-scale metabolic model of yeast to include a detailed description of lipid metabolism for use as a scaffold to integrate omics data. We used iFF708 as a template for building a model based on recent literature that contains new reactions in lipid metabolism and transport relative to all previous models. The new model named iIN800 includes 92 additional ORFs and provides a more detailed structure of lipid metabolism, tRNA synthesis and transport processes than previous models. The biomass composition, which is very important for flux balance analysis and predicting lethality, was also recalculated and improved. iIN800 was validated with large-scale gene deletion data and growth simulation predictions. Simulated intracellular fluxes were also supported by ${ }^{13} \mathrm{C}$-labeling flux experimental data. Finally, we show that the transcriptome data of yeast cultivated under various growth conditions can be integrated with iIN800 to identify lipid related Reporter Metabolites. We anticipate that iIN800 will be useful as a scaffold for integrating multilevel omic data and that this new model will have a significant impact in the emerging field of lipidomics.

\section{Results and discussion \\ Model reconstruction and characteristics of ilN800}

Due to the complexity of compartmentalization used in $i$ ND750 and the smaller scope of iLL672, the metabolic model $i F F 708$ was selected as a template for the development of the model iIN800. Pathway and reaction databases (e.g. KEGG), online resources (e.g. SGD), and literature were used to expand iFF708, with particular focus on lipid metabolism. iIN800 contains 340 total reactions in lipid metabolism, more than at least 143 reactions greater than previous models (Table 1).

To compare metabolic characteristics of the different in silico models, lipid metabolism was classified into unique sub-categories (e.g. mitochondrial fatty acid synthesis, ergosterol biosynthesis) (Table 1). Fatty acid synthesis and elongation accounted for three of these sub-catego- 
Table I: Comparison of the number of lipid metabolism reactions among yeast genome-scale metabolic models

\begin{tabular}{|c|c|c|c|c|}
\hline Model & iFF708 & iLL672 & iND750 & ilN800 \\
\hline Mitochondrial fatty acid synthesis & 14 & 0 & 13 & 45 \\
\hline Cytosolic fatty acid synthesis & 17 & 18 & 27 & 48 \\
\hline Fatty acid elongation & 0 & 4 & 2 & 33 \\
\hline Fatty acid activation and beta-oxidation & 9 & 19 & 53 & 65 \\
\hline Sphingolipid synthesis & 18 & 23 & 37 & 27 \\
\hline Phospholipid and TAG synthesis & 37 & 37 & 35 & 68 \\
\hline Ergosterol biosynthesis & 31 & 28 & 30 & 29 \\
\hline Ergosterol esterification & 0 & 0 & 0 & 2 \\
\hline Lipid degradation & 0 & 0 & 0 & 23 \\
\hline Total & 126 & 129 & 197 & 340 \\
\hline
\end{tabular}

ries. In contrast to previous models, iIN800 incorporates fatty acid biosynthesis in both mitochondria and the cytosol. Fatty acid synthesis, which involves iterative malonyl-CoA condensations that result in a growing chain of fatty acids, is catalyzed by four major enzymes: $\beta$-ketoacylACP synthase (a condensing enzyme), $\beta$-ketoacyl-ACP reductase, $\beta$-dehydroxyacyl-ACP dehydratase and enoylACP reductase. In the cytosol, these enzymes are encoded by the multifunctional FAS1 and FAS2. In the mitochondria, however, fatty acid synthesis is carried out by the products encoded by CEM1, OAR1, HTD2 and ETR1. These ORFs were missing from previous models, which prevented simulation of mitochondrial fatty acid synthesis. Fatty acid elongation, which leads to the production of long-chain fatty acids, was not included in iFF708, but was also updated in iIN800. Including fatty acid elongation resulted in the addition of four major biochemical reaction steps: condensing enzyme, 3-ketoacyl-CoA reductase, enoyl-CoA dehydratase and enoyl-CoA reductase [24]. These reactions are carried out by the enzymes encoded by ELO1, ELO2, ELO3, IFA38 and TSC13. While the gene encoding enoyl-CoA dehydratase has not been identified in S. cerevisiae, the reaction was inferred due to the identification of long chain fatty acids in yeast.

$\beta$-oxidation is the process where fatty acids, after becoming activated in the form of acyl-CoAs, are broken down to make acetyl-CoA, and ultimately energy. FAT1, encoding an enzyme for long-chain fatty acid activation was missing in iFF708 and iLL672. The genes SPS19, ECI1 and DCI1 are also now included in iIN800. As a result, iIN800 can simulate the oxidation of unsaturated fatty acids.

Sphingolipid synthesis reactions were added to iIN800 according to a recently reported model [25], resulting in more sphingolipid reactions than the template iFF708. Sphingolipid synthesis is the only sub-category in iIN800 with a significantly lower reaction tally than $i N D 750$. This is because iND750 incorporated both C24:0 and C26:0 as very long-chain fatty acids (the back bone of sphingolip- ids) to produce ceramides. Because the amount of very long chain fatty acids in $S$. cerevisiae is so low relative to other fatty acid species ( $<2 \%$ of total fatty acid pool) $[24,26]$, iIN800 treats very long chain fatty acids as a single metabolite. As a result, fewer reactions are present in sphingolipid synthesis.

Relative to other models, only minor changes in the biosynthesis of phospholipids and triacylglycerides as well as ergosterol were introduced in iIN800. However, esterification of sterols and degradation of lipids, which were not included in all other previous models, are present in iIN800 (Table 1). Finally, 26 ORFs encoding for tRNA synthesis and one related enzyme, lipoamide dehydrogenase as well as 14 ORFs encoding transporters were also included in iIN800. The additionally included ORFs and their related references as well as detailed comparisons of reactions in lipid metabolism of all reported models are given in Additional files 1 and 2, respectively.

In summary, iIN800 was reconstructed from $17.2 \%$ of the characterized ORFs in yeast and contains 1446 metabolic reactions and 1013 metabolites in total. This model is relatively more comprehensive as compared with previously described models (Table 2). The network characteristics of iIN800 and the starting model iFF708 are shown in Table 3. Within lipid metabolism, we have incorporated many new reactions in mitochondrial fatty acid synthesis, cytosolic fatty acid synthesis, fatty acid elongation, fatty

Table 2: Structure comparison of S. cerevisiae genome-scale metabolic models

\begin{tabular}{lccc}
\hline Model & Genes & Reactions & Metabolites \\
\hline iFF708 & $708(15.2 \%)^{*}$ & 1175 & 825 \\
iLL672 & $672(14.1 \%)^{*}$ & 1038 & 636 \\
iND750 & $750(16.1 \%)^{*}$ & 1489 & 972 \\
iIN800 & $800(17.2 \%)^{*}$ & 1446 & 1013 \\
\hline
\end{tabular}

* percentage of associated ORFs in the model relative to characterized ORFs in the yeast genome 
Table 3: Network characteristics of the reconstructed metabolic network of $S$. cerevisiae strain iFF708 and iIN800

\begin{tabular}{lcc}
\hline Model & iFF708 & iIN800 \\
\hline Metabolites & 825 & 1013 \\
Cytosolic metabolites & 518 & 631 \\
Mitochondrial metabolites & 170 & 228 \\
Extracellular metabolites & 137 & 154 \\
\hline Reactions & 1175 & 1446 \\
Mitochondrial reactions & 104 & 161 \\
Cytosolic reactions & 723 & 906 \\
\hline Exchange fluxes & 348 & 379 \\
Cytosolic exchange fluxes & 286 & 304 \\
Mitochondrial exchange fluxes & 62 & 75 \\
\hline Reactions with ORF assignments & 1075 & 1209 \\
Biochemical and Physical consideration & 140 & 237 \\
\hline
\end{tabular}

acid activation and $\beta$-oxidation, sphingolipid synthesis, ergosterol esterification, and lipid degradation (Table 1). 96 new reactions are derived from biochemical and physical considerations. These reactions mostly describe transportation of fatty acids and lipids across the mitochondria and the plasma membrane. To visualize the model iIN800, we constructed a comprehensive metabolic map using ReMapper software (Figure 1). This visualized map provides a method for globally plotting transcript and flux data onto iIN800. The source file is available for download (see Methods).

\section{Improved biomass equation}

The biomass equation is crucial for using genome-scale models to simulate growth using flux balance analysis (FBA). Therefore, an important consideration in the development of iIN800 was to address the concern that the biomass composition of $S$. cerevisiae changes under different growth conditions. For example, during growth on excess glucose the carbohydrate content increases and during growth on excess ammonium the protein content increases.

To assess the sensitivity of flux simulations using iIN800 towards changes in the macro-molecular composition, we performed constraint-based simulations by varying the protein, RNA, carbohydrate and lipid content of the biomass in physiological relevant ranges based on previous experimental reports [27-29], from 35-65\%, 3.5-12\%, $15-50 \%$ and $2-15 \%$, respectively. Specifically, glucose and ammonium uptake rates were minimized for both glucose- and ammonium-limited growth conditions, respectively, using different macromolecular compositions at fixed growth rates, (note: this is the same mathematical problem as fixing uptake rates and maximizing growth rate). In this way, we could compare the differences between glucose- and ammonium-limited growth conditions. The results are illustrated in Figure 2. An interesting finding was that the protein content strongly affects the uptake rates at both glucose- and ammonium-limited conditions, albeit to a greater extent in ammonium-limited conditions (Fig. 2A). The carbohydrate content on the other hand does not have an impact on the ammonium uptake rate, it strongly impacts the glucose uptake rate (Fig. 2C). The RNA content and the lipid content have only a minor impact on growth (Figures $2 \mathrm{~B}$ and 2D).

In summary, the sensitivity analysis shows that the biomass composition can significantly impact predictions made with genome-scale metabolic models to varying degrees based on different growth conditions. We therefore present new biomass equations to be used under Climited and N-limited growth conditions, respectively. These compositions result from previous studies and our own measurements of lipids and fatty acids across multiple N-limited and C-limited growth conditions (data not shown). Using a separate biomass composition for N-limited cultures has not been proposed previously. The Nlimited biomass equation is therefore new. Relative to previous C-limited biomass compositions, the most dramatic changes in our here proposed biomass equation is with respect to the lipids and fatty acids (Table 4 ). While our sensitivity analysis suggests that these components will most likely only lead to a small improvement in the accuracy of C-limited flux simulations, they may play an important role in lethality prediction by the model, as the addition of extra components in the biomass equation will give a higher resolution.

\section{Growth simulation capability}

In silico genome-scale models are most generally used to predict various phenotypes. These include growth rates and extracellular secretion rates of metabolite products, as well as uptake rates of nutrients. In addition, models can be employed to explore active route(s) in metabolic pathways under certain growth conditions as illustrated for a genome-scale metabolic model of E. coli [30-32] as well as for one of the $S$. cerevisiae genome-scale metabolic models [17].

To validate iIN800, we first investigated the model's ability to simulate aerobic and anaerobic growth in glucoseor ammonium-limited conditions. Several published chemostat datasets were used as experimental references. As shown in Figure 3, the results from the computational growth prediction agreed with experimental measurements. Less than $10 \%$ relative error was observed (Figure 3 ). The details of the simulations and the corresponding reference data are given in Additional file 3. Intracellular 


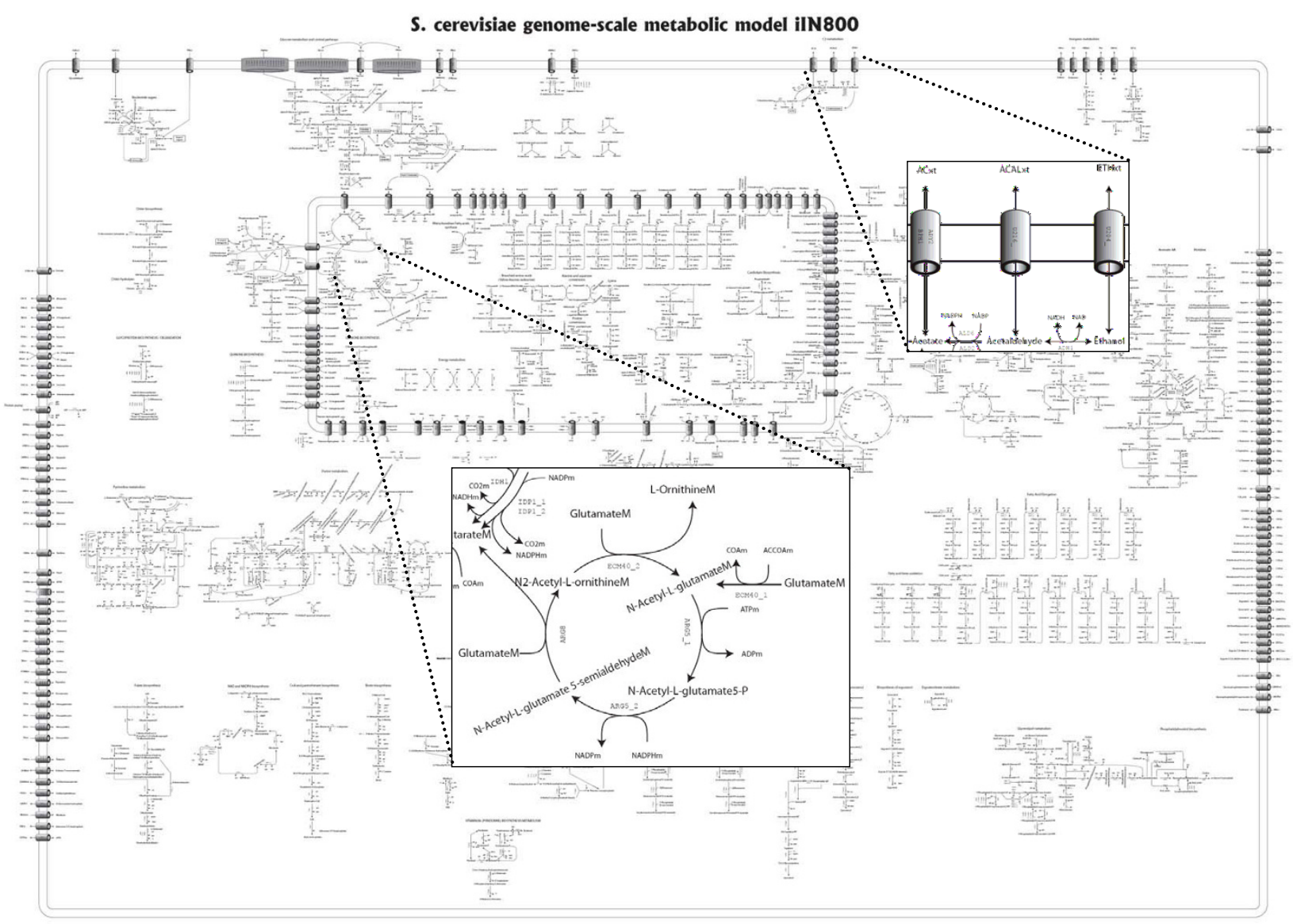

Figure I

The reconstructed $S$. cerevisiae genome-scale metabolic model ilN800.

fluxes can be easily visualized using the ReMapper software and our model (Additional files 4 and 5).

Since the new biomass equations would be expected to impact the overall flux distributions, we used 13C-flux analysis data to further confirm the computed intracellular fluxes. Specifically, fluxes in the central carbon metabolism at two different growth conditions were both measured by 13C-labeling experiments and calculated by FBA using iIN800. The model validation is shown in Figure 4 . There is a high degree of agreement between the predicted and experimental fluxes in the central metabolism, with the exception of fluxes through the pentose phosphate pathway (PPP). Using FBA, the flux through the PPP is largely determined by the requirement for NADPH, and it has earlier been shown difficult to balance NADPH production and consumption [33]. This may explain why the FBA simulations under-predict the flux through this pathway.

\section{Evaluation of large-scale gene deletion}

To verify further iIN800, we investigated the ability of the model to predict for growth viability due to a single gene deletion. In silico deletion phenotype predictions were examined for the new model with cells grown in both minimal media with a sole carbon source (glucose, galactose, glycerol and ethanol) and with rich media (YPD). iIN800 was assessed for its ability to make correct predictions based on experimental data [22,34]. A summary of the in silico single gene deletion predictions are given in Table 5. The overall prediction rate of iIN800, derived from 3392 total predictions, was $89.36 \%$, with $95.50 \%$ sensitivity and $38.69 \%$ selectivity. The evaluation of the mean of a confusion matrix as the geometric mean of iIN800 equals $60.79 \%$. The performance of the iIN800 model has improved by $2 \%$ and $~ 7 \%$ in terms of overall prediction rate compared with the models $i F F 708$ and $i N D 750$, respectively. We believe that the improvement is mainly due to upgrades in the biomass equation, which is 

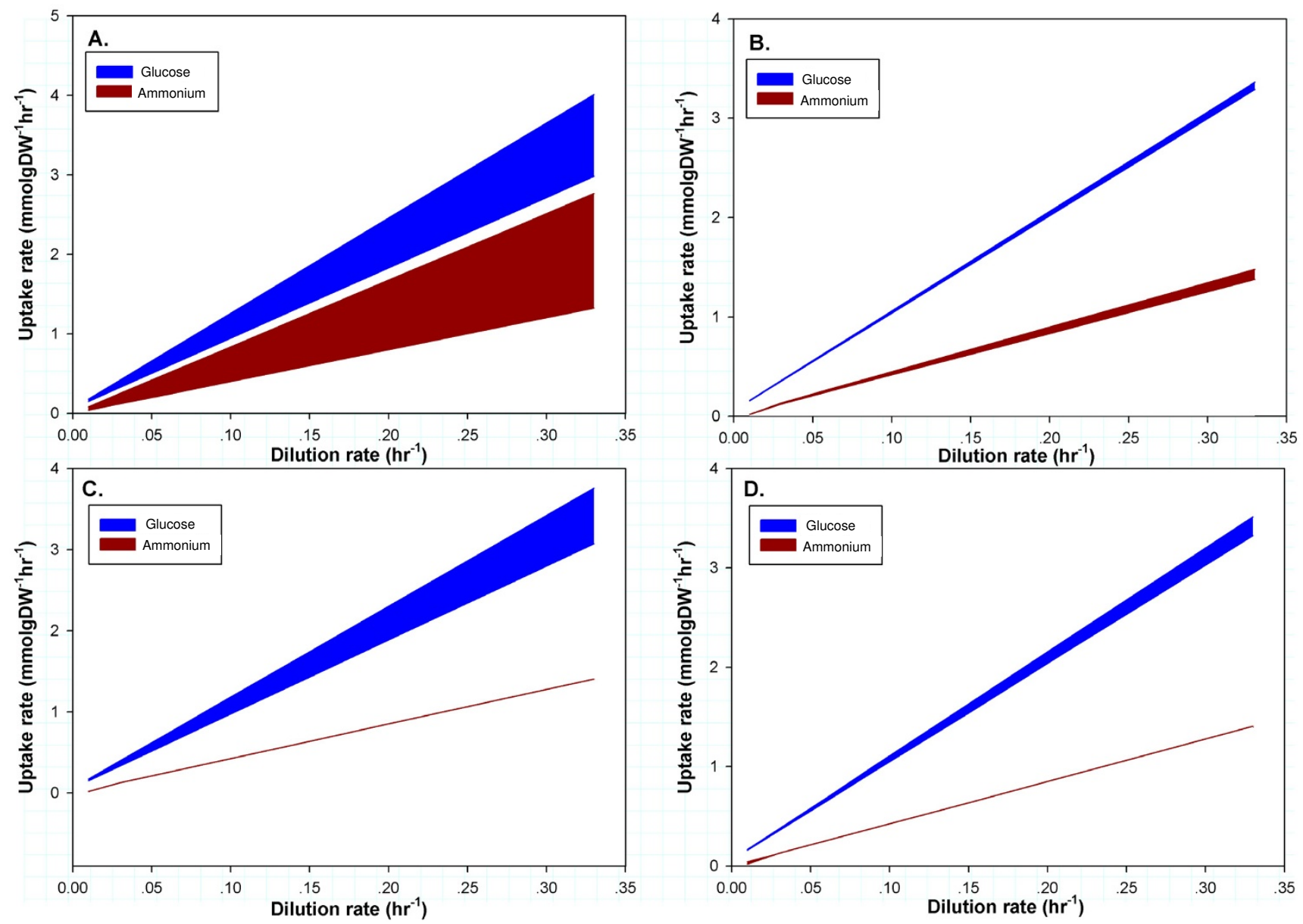

Figure 2

Sensitivity analysis shows the influence of macromolecular composition on the simulated growth rate using ilN800. The simulations were performed for aerobic glucose- and ammonium-limited cultivations by varying (A) the protein content (35-65\%), (B) the RNA content (3.5-12\%), (C) the carbohydrate content (I5-50\%) and (D) the lipid content (2 I5\%).

consistent with results from Kuepfer et al. demonstrating that more accurate biomass compositions lead to improved lethality predictions [22]. The false predictions might be due to missing information in gene regulation, biomass compositions, dead-end reactions and medium composition, especially in the rich medium $[18,19]$

\section{Integration of transcriptome data with genome-scale metabolic models}

Genome-scale metabolic models have shown promise for identifying Reporter Metabolites, defined as metabolites whose neighboring genes in a bipartite metabolic graph are most significantly affected and respond as a group to genetic or environmental perturbations [14]. Such an approach has previously been used to reveal important regulatory hot-spots in metabolism from genome-wide expression data and has demonstrated promise for inte- grating omic data using network topology. To highlight the importance and utility of having a more complete metabolic model in this integrated analysis, the genomescale models iIN800 and iFF708 were used to calculate Reporter Metabolites. Multiple sets of transcriptome data were used for analysis. Lists of the top thirty most significant Reporter Metabolites for several perturbations are compared between iIN800 and iFF708 in Table 6, and Reporter Metabolites unique to iIN800 are marked in bold.

First, transcriptome data from the yeast metabolic cycle [35] were analyzed. Notably, the reporter algorithm identified unique Reporter Metabolites with iIN800 that would have been missed if $i F F 708$ was used as the scaffold (Table 6). The most dramatic difference was observed for the reductive charging phase of the metabolic cell cycle. 
Table 4: Biomass composition

\begin{tabular}{|c|c|c|}
\hline \multirow{2}{*}{$\begin{array}{l}\text { Metabolites } \\
\text { Amino acids }\end{array}$} & \multicolumn{2}{|c|}{ Amount (mmol/gDW) } \\
\hline & Carbon-limited & Nitrogen-limited \\
\hline L-Alanine & 0.357 & 0.252 \\
\hline L-Arginine & 0.136 & 0.098 \\
\hline L-Asparagine & 0.172 & 0.153 \\
\hline L-Aspartate & 0.172 & 0.153 \\
\hline L-Cysteine & 0.043 & 0.044 \\
\hline L-Glutamate & 0.268 & 0.231 \\
\hline L-Glutamine & 0.268 & 0.231 \\
\hline Glycine & 0.325 & 0.278 \\
\hline L-Histidine & 0.075 & 0.071 \\
\hline L-Isoleucine & 0.172 & 0.142 \\
\hline L-Leucine & 0.250 & 0.207 \\
\hline L-Lysine & 0.239 & 0.204 \\
\hline L-Methionine & 0.050 & 0.044 \\
\hline L-Phenylalanine & 0.114 & 0.092 \\
\hline L-Proline & 0.129 & 0.118 \\
\hline L-Serine & 0.254 & 0.225 \\
\hline L-Threonine & 0.197 & 0.160 \\
\hline L-Tryptophan & 0.027 & 0.028 \\
\hline L-Tyrosine & 0.096 & 0.068 \\
\hline Carbohydrates & Carbon-limited & Nitrogen-limited \\
\hline Glycogen & 0.519 & 0.667 \\
\hline alpha,alpha-Trehalose & 0.023 & 0.085 \\
\hline Mannan & 0.821 & 0.994 \\
\hline I,3-beta-D-Glucan & 1.136 & 0.963 \\
\hline RNA & Carbon-limited & Nitrogen-limited \\
\hline$\overline{\mathrm{AMP}}$ & 0.051 & 0.040 \\
\hline GMP & 0.051 & 0.040 \\
\hline CMP & 0.050 & 0.039 \\
\hline UMP & 0.067 & 0.052 \\
\hline DNA & Carbon-limited & Nitrogen-limited \\
\hline$\overline{\mathrm{dAMP}}$ & 0.004 & 0.004 \\
\hline dCMP & 0.002 & 0.003 \\
\hline dTMP & 0.004 & 0.004 \\
\hline dGMP & 0.002 & 0.003 \\
\hline Lipids & Carbon-limited & Nitrogen-limited \\
\hline Phosphatidylcholine & 0.002884 & 0.001660 \\
\hline I-Phosphatidyl-D-myo-inositol & 0.001531 & 0.001656 \\
\hline Phosphatidylserine & 0.000373 & 0.000302 \\
\hline Phosphatidylethanolamine & 0.000697 & 0.000083 \\
\hline Acyl_acids & 0.000206 & 0.000723 \\
\hline Triacylglycerol & 0.000781 & 0.003618 \\
\hline Ergosterol-ester & 0.000812 & 0.004632 \\
\hline Ergosta-5,7,22,24(28)-tetraenol & 0.000125 & 0.000167 \\
\hline Ergosterol & 0.005603 & 0.005155 \\
\hline Zymosterol & 0.000015 & 0.000051 \\
\hline Episterol & 0.000096 & 0.000062 \\
\hline Fecosterol & 0.000114 & 0.000068 \\
\hline Lanosterol & 0.000032 & 0.000074 \\
\hline 4,4-Dimethylzymosterol & 0.000056 & 0.000046 \\
\hline Ceramide-I & 0.000351 & 0.000075 \\
\hline Ceramide-II & 0.000066 & 0.000009 \\
\hline
\end{tabular}




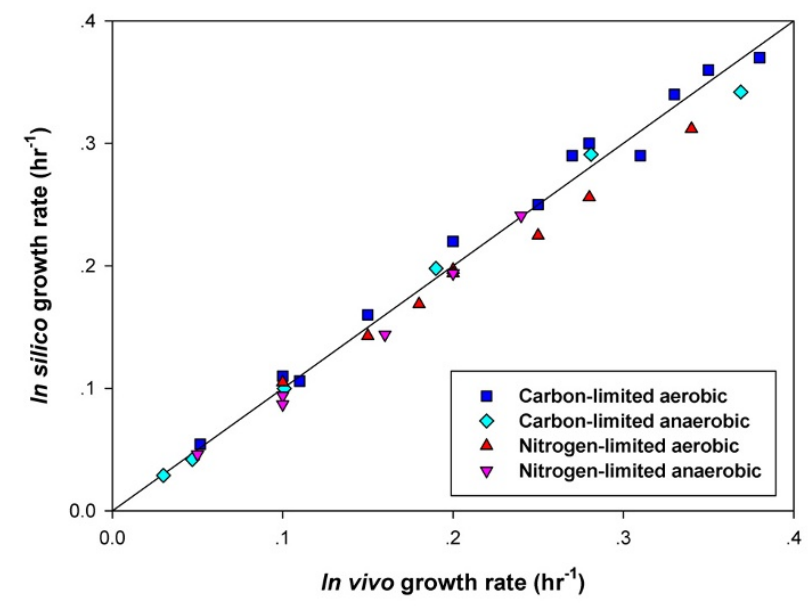

Figure 3

Comparison demonstrating in silico and in vivo growth rates at various cultivation conditions.In silico predictions were performed using FBA with ilN800. Experimental measurements were taken from the literature (see text for references).

While both models revealed the importance of regulation controlling the cellular response at glycogen, trehalose, UDP-glucose, glucose-6-P and glucose nodes, only iIN800 was able to identify key intermediates in $\beta$-oxidation. For example, iIN800 identified trans-3-acyl-CoAs, trans-2acyl-CoAs, 3-keto-acyl-CoAs and some fatty acids as Reporter Metabolites (Table 6). This result demonstrates the advantage of expanding the metabolic model to include a much more detailed description of lipid metabolism. Namely, we can now use the genome-scale metabolic model to identify the regulatory importance of lipid precursors and intermediates at different physiological conditions or at different phases of cellular growth. Searching for highly co-regulated subnetworks that implicate lipid genes is also now possible.

Further demonstrations of the applicability of iIN800 as a scaffold to integrate omic data were performed by analyzing transcriptome data derived from nutrient-limited [36], oxygen-limited [36] and temperature stress conditions [37] Previously, mRNA and protein levels of genes and enzymes in fatty acid catabolism have been shown to be significantly different between carbon-limited and nitrogen limited growth [38]. When comparing these conditions, only iIN800 was able to identify fatty acids as Reporter Metabolites (Table 6). In anaerobic yeast cultivation, oleic acid has to be added to the medium because unsaturated fatty acids synthesis is not possible; therefore, the expression of genes in this pathway is induced by the function of the ORE element [39]. Consistent with this observed cellular response, only iIN800, with identified Reporter Metabolites involved in $\beta$-oxidation (Table 6). Similarly, iIN800 was able to highlight the importance of unsaturated fatty acids when comparing high and low temperature cultivations (Table 6), which is known to be important for maintaining proper membrane structure and fluidity [40].

Without the expanded model, the importance of cellular regulation stemming from lipid metabolism would be missed in analyses where metabolic topology is used for integrating data. As an illustration, we integrated results from our Reporter Metabolite analysis with known protein-protein and protein-DNA interaction networks to infer regulatory structure. First, genes associated to Reporter Metabolites in lipid metabolism unique to iIN800 and determined when comparing carbon- and nitrogen-limited growth (decanoyl-CoA, dodecanoylCoA, trans-2-C141-CoA, trans-2-C161-CoA, trans-2-C181$\mathrm{CoA})$ were identified. These genes were then used to search for highly regulated subnetworks within a proteinprotein and protein-DNA interaction network. By applying a p-value threshold of 0.01 to filter for genes with significant gene expression, we inferred a regulatory network controlling the expression of lipid metabolism genes associated to the Reporter Metabolites (Figure 5). Strikingly, regulators at the top of this hierarchy are consistent with those previously known to be significantly changed between carbon- and nitrogen-limited growth. These include: SNF1, SNF4, MIG1 and ADR1 (glucose repression), OAF1 ( $\beta$-oxidation), and INO1 and INO4 (phospholipid synthesis), among others. Previously reported genome-scale models are not capable of being used as scaffolds for implicating the conditional response of these lipid metabolism regulators because they lack a detailed description of lipid metabolism.

\section{Conclusion}

Genome-scale metabolic models have emerged as a valuable tool in the post-genomic era for illustrating wholecell functions based on the complete network of biochemical reactions. An iterative reconstruction process is required to achieve a comprehensive $S$. cerevisiae genomescale metabolic model. In this work, we focused on improving the formulation of lipid metabolism relative to previously published $S$. cerevisiae genome-scale metabolic models. Validating the model and new biomass equations, the constraint-based simulation of iIN800 showed accurate predictions of cellular growth and is also consistent with ${ }^{13} \mathrm{C}$-labeling experiments. Furthermore, in silico gene essentialness predictions were found to be in high agreement with in vivo results. Finally, we show that iIN800, being more complete, is a better network scaffold for integration of multilevel omics data. 


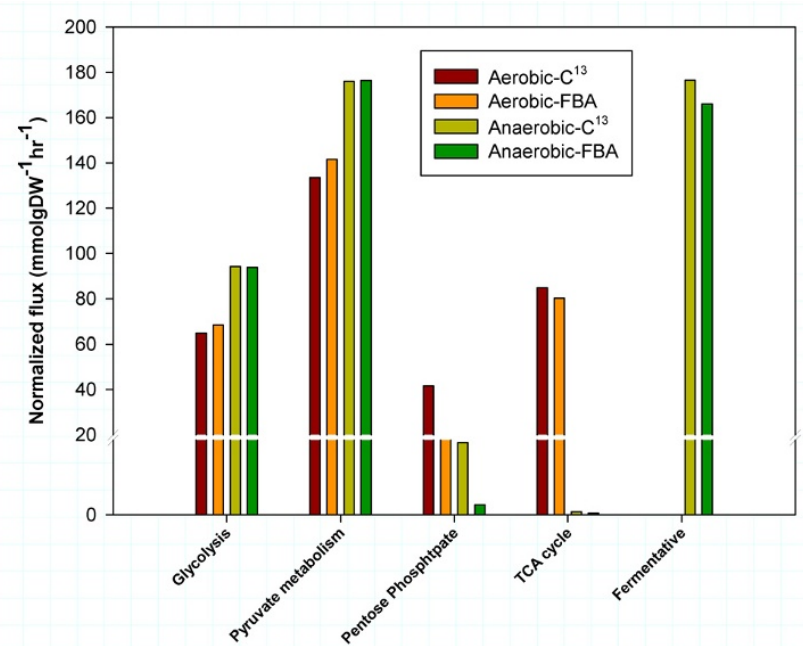

Figure 4

Comparisons of the major intracellular fluxes in the central metabolism calculated using FBA with iIN800 and ${ }^{13} \mathrm{C}$-labeling metabolic flux analysis at a dilution rate of $0.05 \mathrm{~h}^{-1}$ of either aerobic or anaerobic glucose-limited conditions.

In conclusion, by incorporating a more complete description of lipid metabolism, iIN800 is positioned to have a broader impact than previously described yeast models. Its capability of predictions were consistent with a number of experimental data both quantitatively (growth rate) and qualitatively (gene essentialness). Moreover, the new model is positioned to be used for studying the regulation and role of lipid metabolism during different growth conditions. With the high degree of homology in lipid metabolism between yeast and humans and emergence of lipidomics, this is expected to allow for new insights into the connection between lipid metabolism and overall cellular function for industrial and medical applications.

\section{Methods}

\section{Model reconstruction and visualization}

Reconstruction of the $S$. cerevisiae genome-scale metabolic model was done by expanding iFF708 [16]. The additional ORFs included in the expansion procedure were involved in lipid metabolism, tRNA synthesis and lipoamide dehydrogenase. These ORFs were added based on publications listed in Additional file 1. Online resources related to $S$. cerevisiae, such as SGD [41], MIPS [42] and YPD [43], were also used to confirm the existence of the ORFs and their function. Pathway and reaction databases including KEGG [44], ExPASy [45], and Reactome [46], were used together with research papers to identify relevant information of the additional reactions and metabolites, e.g. stoichiometry and co-factor usage. The expanded iFF708, called iIN800, was visualized by Adobe Illustrator software (Adobe Systems), and then converted to EPS format (Adobe Systems) format which is downloadable as Additional file 6. In this visualization file, it is possible to overlay information about transcription, fluxes etc. A detailed list of metabolic reactions in iIN800 is provided as Additional file 7.

\section{Metabolic modeling and simulations}

The reaction set in iIN800 was used for construction of a stoichiometric matrix $S(\mathrm{~m} \times \mathrm{n})$. In the stoichiometric matrix, $m=1013$, which is the number of metabolites, and $n=1446$, which is the number of metabolic reactions. With an assumption of steady state for all metabolite pools, a linear equation constraining the fluxes in the metabolic network is obtained $[30,47]$ :

$$
S \cdot v=0
$$

Here $v$ is a vector that contains all the fluxes in the model. Equation (1) has a large number of degrees of freedom, i.e. it is an underdetermined problem, and linear programming was employed to solve the equation system by maximizing an objective function $Z$ (equal to the growth rate), an approach generally referred to as flux balance analysis (FBA) [30,47]. The problem formulation is described below.

Maximize:

$$
Z=\omega \cdot v
$$

Subject to:

$$
\begin{gathered}
S \cdot \boldsymbol{v}=\mathbf{0} \\
\alpha \leq \boldsymbol{v} \leq \beta
\end{gathered}
$$

where $\alpha$ and $\beta$ are lower and upper bounds of fluxes respectively, $\omega$ is a weight vector indicating an amount of desired metabolites for biomass synthesis. For irreversible fluxes semi-positive infinite boundary was applied as $0 \leq$ $\boldsymbol{v} \leq \infty$, and fully infinite boundaries was applied as $-\infty \leq \boldsymbol{v}$ $\leq \infty$ for reversible fluxes. The problem was solved by using the commercial linear programming software package LINDO (Lindo systems Inc., Chicago, IL, USA). The calculated intracellular fluxes were overlaid on the visualized genome-scale map as described previously by the ReMapper software (The software has been developed for visualization of multilevel omics data onto a metabolic map.).

\section{Calculation of biomass composition and sensitivity analysis}

The biomass composition was re-calculated in order to improve the prediction of the model during growth at different nutrition-limitations, i.e. carbon- and nitrogen-lim- 
Table 5: Summary of large-scale single gene deletion evaluation of S. cerevisiae ilN800.

\begin{tabular}{|c|c|c|c|c|c|c|c|}
\hline \multirow[b]{2}{*}{ Evaluation } & \multirow[b]{2}{*}{ Glucose* } & \multicolumn{3}{|c|}{ Minimal media on } & \multicolumn{3}{|c|}{ Rich media } \\
\hline & & Glucose** & Galactose & Glycerol & Ethanol & YPD & Total \\
\hline TP & 468 & 469 & 461 & 461 & 463 & 567 & 2889 \\
\hline TN & 23 & 23 & 20 & 17 & 21 & 38 & 142 \\
\hline $\mathbf{F P}$ & 37 & 37 & 42 & 45 & 43 & 21 & 225 \\
\hline FN & 14 & 13 & 19 & 19 & 15 & 56 & 136 \\
\hline Number of deletions & 542 & 542 & 542 & 542 & 542 & 682 & 3392 \\
\hline Positive prediction rate & 92.67 & 92.69 & 91.65 & 91.11 & 91.50 & 96.43 & 92.77 \\
\hline Negative prediction rate & 62.16 & 63.89 & 51.28 & 47.22 & 58.33 & 40.43 & 51.08 \\
\hline Accuracy & 90.59 & 90.77 & 88.75 & 88.19 & 89.30 & 88.71 & 89.36 \\
\hline Sensitivity & 97.10 & 97.30 & 96.04 & 96.04 & 96.86 & 91.01 & 95.50 \\
\hline Selectivity & 38.33 & 38.33 & 32.26 & 27.42 & 32.81 & 64.41 & 38.69 \\
\hline Geometric mean & 61.01 & 61.07 & 55.66 & 51.32 & 56.38 & 76.56 & 60.79 \\
\hline
\end{tabular}

$*=$ Aerobic growth, $* *=$ Anaerobic growth

$\mathrm{TP}=$ true positive, $\mathrm{TN}=$ true negative, $\mathrm{FP}=$ false positive, $\mathrm{FN}=$ false negative.

ited growth condition. The contents of macro-molecules were extracted from the thesis of Schulze [27] who measured the biomass composition at a dilution rate of $0.1 \mathrm{~h}-$ 1 . The calculations were performed as described previously [16]. The calculation of protein precursors, i.e. amino acids, and carbohydrate precursors, i.e. trehalose, glycogen, manna and glucan, were adopted from Schulze's work [27]. Deoxyribonucleotide and ribonucleotide compositions were calculated from the study of Vaughan-Martini and co-workers [48]. Lipid compositions were calculated from our own measurements of structural lipidomics, which contains phospholipids, triacylglycerol, sterols, sterol-esters, sphingolipids, free fatty acids and fatty acids composition of all measured lipid classes (unpublished data). The impact of the macromolecular composition on biomass yield was explored in aerobically glucose- and ammonium-limited conditions by fixing the specific growth rate and then minimizing the glucose and ammonium uptake rates at both glucose- and ammonium-limited growth conditions. Four parameters were evaluated, namely the protein, RNA, carbohydrate and lipid content of the biomass.

\section{Growth simulations}

The metabolic capabilities of iIN800 were evaluated by using FBA and linear programming to simulate the biomass flux representing the in silico growth rate, which were derived by maximizing the biomass production. Data from various carbon-limited and nitrogen-limited chemostat experiments performed at either aerobic or anaerobic growth condition were taken from the literature for comparisons (see references in Additional file 3). These data were used to validate the metabolic capabilities of the model by comparing in silico biomass yields with in vivo biomass yields. The in silico biomass yields were calculated by fixing measurable uptake rates of extracellular metabolites, such as glucose, ammonium and oxygen, as well as secretions rates of acetate, glycerol, ethanol, succinate, pyruvate and carbon dioxide. The biomass equation (or flux), which was the objective function, was changed depending on the growth conditions evaluated according to the data provide in Table 4.

\section{Large-scale gene essentiality simulations}

The impact of individual gene deletions on cell growth of iIN800 was evaluated by eliminating the reaction(s) corresponding to each gene in the model from the stoichiometric matrix $S$ and then simulating growth of the mutant by FBA. The in silico gene essentialities were simulated for growth on rich- and minimal-medium. For minimal media, different carbon sources (glucose, galactose, glycerol and ethanol), ammonium, sulphate and phosphate were evaluated. For rich media, the uptake fluxes of amino acids, purines and pyrimidines were added as additional constraints as previously described [18]. The in silico simulations were compared to experimental data available in the MIPS and SGD databases and from competitive growth assays [34] as well as yeast mutant array experiments [22]. The power of iIN800 to predict gene essentiality was evaluated based on the criteria defined as follows:

$$
\begin{gathered}
\text { Accuracy }=(\mathrm{TP}+\mathrm{TN}) /(\mathrm{TP}+\mathrm{TN}+\mathrm{FP}+\mathrm{FN}) \\
\text { Sensitivity }=\mathrm{TP} /(\mathrm{TP}+\mathrm{FN}) \\
\text { Specificity }=\mathrm{TN} /(\mathrm{TN}+\mathrm{FP}) \\
\text { Positive predictive value }=\mathrm{TN} /(\mathrm{TP}+\mathrm{FP}) \\
\text { Negative predictive value }=\mathrm{TN} /(\mathrm{TN}+\mathrm{FN}) \\
\text { Geometric mean }=(\text { Sensitivity } \cdot \text { Specificity })^{1 / 2}
\end{gathered}
$$




\begin{tabular}{|c|c|c|c|c|c|}
\hline \multicolumn{2}{|c|}{ Oxidative phase ${ }^{l}$} & \multicolumn{2}{|c|}{ Reductive building phase } & \multicolumn{2}{|c|}{ Reductive charging Phase } \\
\hline ilN800 & iFF708 & ilN800 & iFF708 & ilN800 & iFF708 \\
\hline AMP & IMP & AMPM & AMPM & Dodecanoyl-CoA* & Acyl-CoA \\
\hline IMP & Xanthosine 5'-phosphate & PyrophosphateM & tRNAM & Decanoyl-CoA* & alpha,alpha-Trehalose \\
\hline Pyrophosphate & L-Methionine & ATPM & PyrophosphateM & Trans-3-CI6-CoA* & Glycogen \\
\hline L-Methionine & 5-Phospho-alpha-D-ribose I-PP & tRNAM & Porphobilinogen & Trans-3-CI8-CoA* & $\begin{array}{l}\text { alpha,alpha'-Trehalose 6- } \\
\text { phosphate }\end{array}$ \\
\hline Xanthosine 5'-phosphate & L-Aspartate & $\mathrm{H}+\mathrm{M}$ & L-TryptophanM & Trans-3-CI4-CoA* & alpha-D-Glucose \\
\hline ATP & Sulfate & NADHM & L-Tryptophanyl-tRNA(Trp)M & alpha,alpha-Trehalose & Oxalosuccinate \\
\hline 5-Phospho-alpha-D-ribose I-PP & Homocysteine & Porphobilinogen & Dolichyl beta-D-mannosyl-P & Glycogen & 3-Oxoacyl-CoA \\
\hline L-Serine & AMP & Dolichyl beta-D-mannosyl-P & Mannan & $\begin{array}{l}\text { alpha,alpha'-Trehalose 6- } \\
\text { phosphate }\end{array}$ & a Long-chain carboxylic acid \\
\hline L-Aspartate & $\mathrm{H}+\mathrm{EXT}$ & L-Tryptophanyl-tRNA(Trp)M & Xanthine & Oxalosuccinate & Carnitine \\
\hline $\mathrm{H}+\mathrm{EXT}$ & 3-Phosphonooxypyruvate & Mannan & L-Asparaginyl-tRNA(Asn)M & Trans-2-CI4-CoA* & alpha-D-Glucose 6-phosphate \\
\hline Homocysteine & $\begin{array}{l}\text { N6-(L-I,3-Dicarboxypropyl)-L- } \\
\text { lysine }\end{array}$ & tRNA(Ile)M* & $H+M$ & Trans-2-CI6-CoA* & UDPglucose \\
\hline Sulfate & 5,10-Methylenetetrahydrofolate & L-Isoleucyl-tRNA(Ile)M* & Dolichyl phosphate & Trans-2-CI8-CoA* & Isocitrate \\
\hline L-Glutamine & Aminoimidazole ribotide & tRNA(Thr)M* & all-trans-Nonaprenyl-PP & 3-keto-Dodecanoyl-CoA* & D-Glucose I-phosphate \\
\hline L-Cysteine & L-Cystathionine & L-Threonyl-tRNA(Thr)M* & NADHM & 3-keto-Decanoyl-CoA* & CoAM \\
\hline L-Asparagine & L-Serine & Xanthine & ATPM & 3-keto-Octanoyl-CoA* & Acetyl-CoAM \\
\hline S-Adenosyl-L-methionine & Uracil & Dolichyl phosphate & D-Mannose 6-phosphate & 3-keto-Hexanoyl-CoA* & CoA \\
\hline Uracil & Sulfite & all-trans-Nonaprenyl-PP & UbiquinolM & 3-keto-Butanoyl-CoA* & O-Acetylcarnitine \\
\hline $\begin{array}{l}5,10- \\
\text { Methylenetetrahydrofolate }\end{array}$ & 5-amino-4-imidazolecarboxylate & L-Asparaginyl-tRNA(Asn)M & Ubiquinone-9M & Dodecanoic_acid* & Succinate \\
\hline 3-Phosphonooxypyruvate & $\begin{array}{l}\text { 2-Hydroxybutane-I,2,4- } \\
\text { tricarboxylate }\end{array}$ & tRNA(Phe)M* & $\mathrm{CO} 2 \mathrm{M}$ & Carnitine & $\begin{array}{l}\text { (S)-3-Hydroxy-3- } \\
\text { methylglutaryl-CoA }\end{array}$ \\
\hline $\begin{array}{l}\text { N6-(L-I,3-Dicarboxypropyl)-L- } \\
\text { lysine }\end{array}$ & S-Adenosyl-L-methionine & $\begin{array}{l}\text { L-Phenylalanyl- } \\
\text { tRNA(Phe)M* }\end{array}$ & Guanosine & alpha-D-Glucose & $\mathrm{NAD+}$ \\
\hline L-Cystathionine & L-Asparagine & $\begin{array}{l}\text { Intermediate_Methylzymoster } \\
\text { ol_II }\end{array}$ & IsocitrateM & Trans-2-4-diene-CoA* & $\mathrm{H} 2 \mathrm{O} 2$ \\
\hline $\mathrm{NH} 3$ & 5-Phosphoribosylamine & Intermediate_Zymosterol_II & GTPM & Isocitrate & Malate \\
\hline tRNA(Phe)* & GlycineM & UbiquinolM & GDPM & alpha-D-Glucose 6-phosphate & Maltose \\
\hline $\begin{array}{l}\text { L-Phenylalanyl- } \\
\text { tRNA(Phe)* }\end{array}$ & Guanine & D-Mannose 6-phosphate & ITPM & UDPglucose & (3S)-3-Hydroxyacyl-CoA \\
\hline Tetrahydrofolate & L-Histidine & Ubiquinone-9M & IDPM & D-Glucose I-phosphate & GLCxt \\
\hline Guanine & $\begin{array}{l}\text { NI-(5'- } \\
\text { phosphoribosyl)acetamidine }\end{array}$ & tRNA(Asp)M* & ITP & O-Acetylcarnitine & Glycerone phosphate \\
\hline Sulfite & Tetrahydrofolate & L-Aspartyl-tRNA(Asp)M* & IDP & Tetradecanoyl-CoA* & O-AcetylcarnitineM \\
\hline L-Histidine & alpha-D-Glutamyl phosphate & tRNA(Pro) $M^{*}$ & Phosphatidate & Decanoic_acid* & CarnitineM \\
\hline $\begin{array}{l}\text { 5-amino-4- } \\
\text { imidazolecarboxylate }\end{array}$ & HomoisocitrateM & L-Prolinyl-tRNA(Pro)M* & $\mathrm{CIOOACPm}$ & $\begin{array}{l}\text { (S)-3-Hydroxy-3- } \\
\text { methylglutaryl-CoA }\end{array}$ & D-Galactose \\
\hline GlycineM & GMP & Pyrophosphate & Dodecanoyl-ACPM & $\mathrm{H} 2 \mathrm{O} 2$ & SuccinateM \\
\hline
\end{tabular}

* Metabolite is contained in ilN800 only

I = data from Tu, B. P., A. Kudlicki, et al. (2005) 
Table 6: Top thirty Reporter Metabolites calculated from various perturbations. The Reporter Metabolite algorithm was performed with ilN800 and iFF708. (Continued)

\begin{tabular}{|c|c|c|c|c|c|}
\hline \multicolumn{2}{|c|}{ Carbon- and Nitrogen-limited ${ }^{2}$} & \multicolumn{2}{|c|}{ Aerobic and Anaerobic ${ }^{2}$} & \multicolumn{2}{|c|}{ Temperature $\left(30^{\circ} \mathrm{C} \text { and } 15^{\circ} \mathrm{C}\right)^{3}$} \\
\hline ilN800 & iFF708 & ilN800 & iFF708 & ilN800 & iFF708 \\
\hline Glyoxylate & Glyoxylate & Oxygen & Ferricytochrome cM & IMP & IMP \\
\hline GLUxt & L-Phenylalanine & Ferricytochrome cM & Ferrocytochrome cM & Tetrahydrofolate & Tetrahydrofolate \\
\hline Isocitrate & GLUxt & Ferrocytochrome cM & Ubiquinone-9M & alpha,alpha-Trehalose & alpha,alpha-Trehalose \\
\hline ALAxt & Isocitrate & Ubiquinone-9M & Oxygen & $\begin{array}{l}\text { Hexadecanoyl-9-ene- } \\
\text { CoA* }\end{array}$ & D-Erythrose 4-phosphate \\
\hline Malate & ALAxt & UbiquinolM & UbiquinolM & $\begin{array}{l}\text { Octadecanoyl-9-ene- } \\
\text { CoA* }\end{array}$ & L-OrnithineM \\
\hline Allantoate & Allantoate & ADPM & ADPM & $\begin{array}{l}\text { Tetradecanoyl-9-ene- } \\
\text { CoA* }\end{array}$ & Xanthosine 5'-phosphate \\
\hline SERxt & Malate & $H+M$ & $\mathrm{H}+\mathrm{M}$ & D-Erythrose 4-phosphate & $\begin{array}{l}\text { N6-(L-I,3-Dicarboxypropyl)- } \\
\text { L-lysine }\end{array}$ \\
\hline L-Alanine & L-Alanine & Dodecanoyl-CoA* & $\mathrm{FADH} 2 \mathrm{M}$ & L-OrnithineM & $\mathrm{NADH}$ \\
\hline Decanoyl-CoA* & SERxt & FumarateM & FumarateM & Xanthosine 5'-phosphate & URIxt \\
\hline ASNxt & ASNxt & OrthophosphateM & OrthophosphateM & $\begin{array}{l}\text { N6-(L-I,3-Dicarboxypropyl)- } \\
\text { L-lysine }\end{array}$ & $\begin{array}{l}\text { I-Phosphatidyl-ID-myo- } \\
\text { inositol 4-P }\end{array}$ \\
\hline GLNxt & GLNxt & $\mathrm{FADH} 2 \mathrm{M}$ & Sphinganine I-phosphate & URIxt & Homocysteine \\
\hline ILExt & ILExt & $\begin{array}{l}\text { Hexadecanoyl-9-ene- } \\
\text { CoA* }\end{array}$ & ATPM & Homocysteine & $\begin{array}{l}\text { I-Phosphatidyl-D-myo- } \\
\text { inositol 4,5-PP }\end{array}$ \\
\hline VALxt & VALxt & $\begin{array}{l}\text { Octadecanoyl-9-ene- } \\
\text { CoA* }\end{array}$ & Fumarate & Octadecanoyl-CoA & N-Acetyl-L-glutamateM \\
\hline Trans-2-CI6I-CoA* & Ferricytochrome cM & $\begin{array}{l}\text { Tetradecanoyl-9-ene- } \\
\text { CoA* }\end{array}$ & Glyoxylate & N-Acetyl-L-glutamateM & Dihydrofolate \\
\hline Trans-2-CI8I-CoA* & Ferrocytochrome cM & Sphinganine I-phosphate & Isocitrate & Dihydrofolate & N2-Acetyl-L-ornithineM \\
\hline Trans-2-CI4I-CoA* & PHExt & $\begin{array}{l}\text { Phytosphingosine I- } \\
\text { phosphate }\end{array}$ & ERGOSTxt & N2-Acetyl-L-ornithineM & Anthranilate \\
\hline PHExt & L-Asparagine & Tetradecanoyl-Co & ZYMSTxt & Anthranilate & S-Adenosyl-L-homocysteine \\
\hline Ferricytochrome cM & Allantoin & Fumarate & NAD+ & $\begin{array}{l}\text { Hexadecanoyl-9- } \\
\text { ene_acid* }\end{array}$ & UREAxt \\
\hline Ferrocytochrome cM & LEUxt & Trans-2-CI6I-CoA* & FADM & Octadecanoyl-9-ene_acid* & L-Aspartate \\
\hline FRUXt & FRUxt & Trans-2-CI8I-CoA* & 6-Phospho-D-gluconate & S-Adenosyl-L-homocysteine & N(pai)-Methyl-L-histidine \\
\hline Allantoin & Succinate & Trans-2-CI4I-CoA* & I,3-Diaminopropane & $\mathrm{NADH}$ & Adenosine $3^{\prime}, 5^{\prime}$-bisphosphate \\
\hline LEUxt & HISxt & Glyoxylate & sn-Glycerol 3-phosphate & UREAxt & 4-imidazolecarboxylate \\
\hline Succinate & TYRxt & sn-Glycerol 3-phosphate & O-Acetylcarnitine & L-Aspartate & 3-Methyl-2-oxobutanoateM \\
\hline HISxt & METxt & Isocitrate & Ethanol & $\begin{array}{l}\text { I-Phosphatidyl-D-myo- } \\
\text { inositol-3-P }\end{array}$ & Tetrahydrofolyl-[Glu](n) \\
\hline Dodecanoyl-CoA* & GLYXt & ERGOSTxt & DIPEPxt & N(pai)-Methyl-L-histidine & 2-Phenylacetamide \\
\hline PROxt & ASPxt & ZYMSTXt & Dipeptide & Adenosine 3',5'-bisphosphate & Phenylacetic acid \\
\hline alpha-D-Mannose & GLCxt & I,3-Diaminopropane & OPEPxt & L-Asparagine & Indole-3-acetamide \\
\hline Trans-3-CI6-CoA* & L-Tyrosine & 6-Phospho-D-gluconate & Oligopeptide & C24-CoA* & Indole-3-acetate \\
\hline Trans-3-CI8-CoA* & PROxt & $\mathrm{H} 2 \mathrm{O} 2$ & PEPT Xt & $\begin{array}{l}\text { I-(5-Phospho-D-ribosyl)-5- } \\
\text { amino }\end{array}$ & Urea-I-carboxylate \\
\hline Trans-3-CI4-CoA* & alpha-D-Mannose & Trans-3-Cl6-CoA* & Sphinganine & 3-Methyl-2-oxobutanoateM & PhosphatidylserineM \\
\hline
\end{tabular}

* Metabolite is contained in ilN800 only

$2=$ Tai, S. L., V. M. Boer, et al. (2005)

$3=$ Pizarro, F., M.C. Jewett, et al. (2008) 


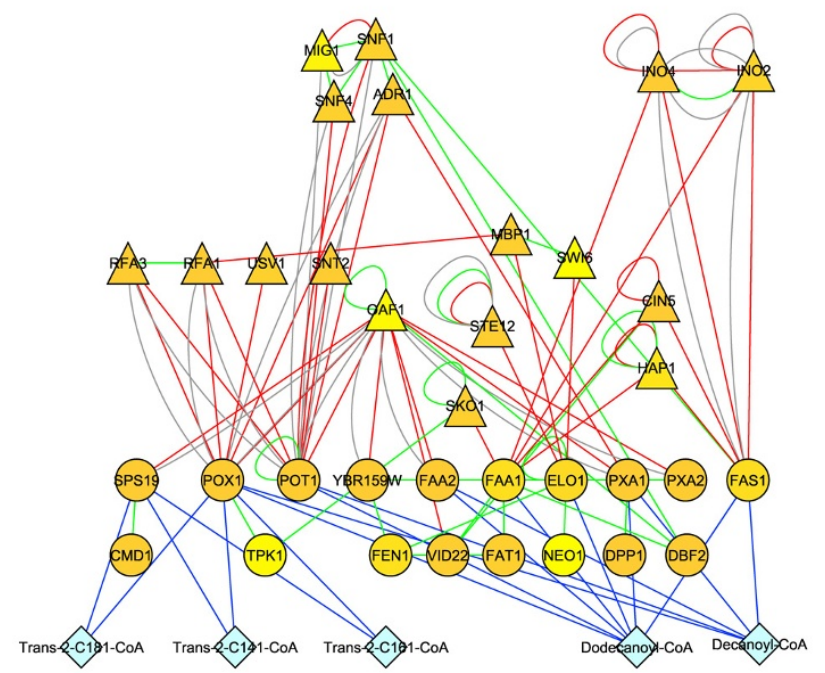

Figure 5

Regulatory module implicated in the control of lipid metabolism genes associated to ilN800 Reporter Metabolites, which were determined by comparing $\mathbf{N}$-limited and $\mathbf{C}$-limited growth. Without the expanded model ilN800, the importance of cellular regulation stemming from lipid metabolism would be missed. High scoring Reporter Metabolites (diamonds), metabolic genes associated to Reporter Metabolites (circles), and genes encoding regulators (triangles). The blue, red, gray and green edges represent metabolite-gene interactions from the genomescale metabolic model, protein-DNA interactions from ChIPCHIP data, protein-DNA interactions from YPD and proteinprotein interactions from BioGRID, respectively.

where $\mathrm{TP}=$ true positive, $\mathrm{TN}=$ true negative, $\mathrm{FP}=$ false positive, $\mathrm{FN}=$ false negative. Positive and negative values referred to viable and lethal phenotype, respectively.

\section{Reporter Metabolite determination}

Published microarray data were retrieved from Gene Expression Omnibus (GEO) [49]. The CEL files were normalized by the dChip software [50] in order to minimize overall intensity variation among a set of chips. The statistical test of significance was done by ANOVA or student ttest for p-value calculation.

Briefly, we describe the Reporter Metabolite calculations. The genome-scale model was converted to a bipartite undirected graph. In this graph each metabolite node has as neighbors the enzymes catalyzing the formation and consumption of the metabolite. The transcriptome data were mapped on the enzyme nodes using the significant values of gene expression. The normal commutative distribution was used to convert the p-values to a Z-score for further calculations. To identify an importance of metabolites in the metabolic network of the particular experi- mental conditions, the reporter algorithm was applied as described earlier [14].

\section{Inferring regulatory modules from Reporter Metabolites}

The interactome network was initially constructed with data obtained from YPD [43], ChIP-chip databases [51] (protein-DNA interaction) and BioGRID [52] (proteinprotein interaction). The candidate genes of high scoring Reporter Metabolites were retrieved from the bipartite metabolite-gene encoding enzyme interaction graph. They were then used to identify subnetworks from the interactome network [53]. Significantly changing p-values from microarray data were mapped on the subnetwork and then also genes having a p-value $<0.01$ directly connected with the Reporter Metabolites. The module was visualized by Cytoscape software [54].

\section{Authors' contributions}

IN designed the study, performed the metabolic reconstruction and validation, and contributed to manuscript writing. MCJ carried out the $\mathrm{C}^{13}$-labeling flux experiments, helped curate the model and contributed to manuscript writing. $\mathrm{AM}, \mathrm{CT}, \mathrm{KL}$ and $\mathrm{SC}$ contributed to the manuscript preparations, JN and SB participated in the concept and design of the study. All authors read and approved the final manuscript.

\section{Additional material}

\section{Additional file 1}

Additional ORFs. List if additional ORFs and their references containing in iIN800.

Click here for file

[http://www.biomedcentral.com/content/supplementary/17520509-2-71-S1.pdf]

\section{Additional file 2}

Lipid metabolism reactions and comparison. Comparison of lipid metabolism reactions of all $\mathrm{S}$. cerevisiae genome-scale models.

Click here for file

[http://www.biomedcentral.com/content/supplementary/17520509-2-71-S2.zip]

\section{Additional file 3}

Growth simulation results. Growth simulations and comparison with experimental measurements.

Click here for file

[http://www.biomedcentral.com/content/supplementary/17520509-2-71-S3.pdf]

\section{Additional file 4}

Aerobic Flux distribution. Visualization of flux distribution of aerobic growth mapping on Figure 1.

Click here for file

[http://www.biomedcentral.com/content/supplementary/17520509-2-71-S4.pdf] 


\section{Additional file 5}

Anaerobic Flux distribution. Visualization of flux distribution of anaerobic growth mapping on Figure 1.

Click here for file

[http://www.biomedcentral.com/content/supplementary/17520509-2-71-S5.pdf]

\section{Additional file 6}

High resolution file of Figure 1. High resolution of S. cerevisiae metabolic map is provided as EPS format.

Click here for file

[http://www.biomedcentral.com/content/supplementary/1752-

0509-2-71-S6.eps]

\section{Additional file 7}

iIN800 model. List of all participated reactions in iIN800 model.

Click here for file

[http://www.biomedcentral.com/content/supplementary/1752-

0509-2-71-S7.pdf]

\section{Acknowledgements}

The authors gratefully thank Mikael Rørdam Andersen and Kiran Raosaheb Patil for providing the ReMapper and the Reporter software, respectively. This work is supported by a grant from the National Center for Genetic Engineering and Biotechnology (BIOTEC) (grant number BT-B-06-NG-B54602). Intawat Nookaew gratefully acknowledges financial support by Thai Graduate Student Institute Science and Technology (TGIST). Michael C. Jewett is grateful to the NSF International Research Fellowship Program for supporting his work.

\section{References}

I. Nielsen J, Jewett MC: Impact of systems biology on metabolic engineering of Saccharomyces cerevisiae. FEMS Yeast Res 2007.

2. Botstein D, Chervitz SA, Cherry JM: Yeast as a model organism. Science 1997, 277(5330): I259-1260.

3. Pena-Castillo L, Hughes TR: Why are there still over 1000 uncharacterized yeast genes? Genetics 2007, 176(I):7-14.

4. Goffeau A, Barrell BG, Bussey H, Davis RW, Dujon B, Feldmann H, Galibert F, Hoheisel JD, Jacq C, Johnston M, Louis EJ, Mewes HW, Murakami Y, Philippsen P, Tettelin H, Oliver SG: Life with 6000 genes. Science 1996, 274(5287):546, 563-7.

5. Bassett DE Jr., Boguski MS, Hieter P: Yeast genes and human disease. Nature 1996, 379(6566):589-590.

6. Foury F: Human genetic diseases: a cross-talk between man and yeast. Gene 1997, 195(I): $1-10$.

7. Steinmetz LM, Scharfe C, Deutschbauer AM, Mokranjac D, Herman ZS, Jones T, Chu AM, Giaever G, Prokisch H, Oefner PJ, Davis RW: Systematic screen for human disease genes in yeast. Nat Genet 2002, 3 I (4):400-404.

8. German JB, Gillies LA, Smilowitz JT, Zivkovic AM, Watkins SM: Lipidomics and lipid profiling in metabolomics. Curr Opin Lipido 2007, I 8(I):66-7I.

9. Vigh L, Escriba PV, Sonnleitner A, Sonnleitner M, Piotto S, Maresca B, Horvath I, Harwood JL: The significance of lipid composition for membrane activity: new concepts and ways of assessing function. Prog Lipid Res 2005, 44(5):303-344.

10. Scherzer CR, Feany MB: Yeast genetics targets lipids in Parkinson's disease. Trends Genet 2004, 20(7):273-277.

II. Mutch DM, Fauconnot L, Grigorov M, Fay LB: Putting the 'Ome' in lipid metabolism. Biotechnol Annu Rev 2006, I 2:67-84.

12. Gaspar ML, Aregullin MA, Jesch SA, Nunez LR, Villa-Garcia M, Henry SA: The emergence of yeast lipidomics. Biochim Biophys Acta 2007, I 77I(3):24|-254
13. Patil KR, Akesson M, Nielsen J: Use of genome-scale microbial models for metabolic engineering. Curr Opin Biotechnol 2004, I 5(I):64-69.

14. Patil KR, Nielsen J: Uncovering transcriptional regulation of metabolism by using metabolic network topology. Proc Natl Acad Sci U S A 2005, 102(8):2685-2689.

15. Cakir T, Patil KR, Onsan Z, Ulgen KO, Kirdar B, Nielsen J: Integration of metabolome data with metabolic networks reveals reporter reactions. Mol Syst Biol 2006, 2:50.

16. Forster J, Famili I, Fu P, Palsson BO, Nielsen J: Genome-scale reconstruction of the Saccharomyces cerevisiae metabolic network. Genome Res 2003, 13(2):244-253.

17. Famili I, Forster J, Nielsen J, Palsson BO: Saccharomyces cerevisiae phenotypes can be predicted by using constraint-based analysis of a genome-scale reconstructed metabolic network. Proc Natl Acad Sci U S A 2003, I00(23): | 3 | 34- 13 | 39.

18. Forster J, Famili I, Palsson BO, Nielsen J: Large-scale evaluation of in silico gene deletions in Saccharomyces cerevisiae. Omics 2003, 7(2): 193-202.

19. Duarte NC, Herrgard MJ, Palsson BO: Reconstruction and validation of Saccharomyces cerevisiae iND750, a fully compartmentalized genome-scale metabolic model. Genome Res 2004, I 4(7): | 298-1309.

20. Duarte NC, Palsson BO, Fu P: Integrated analysis of metabolic phenotypes in Saccharomyces cerevisiae. BMC Genomics 2004, 5(I):63.

21. Herrgard MJ, Lee BS, Portnoy V, Palsson BO: Integrated analysis of regulatory and metabolic networks reveals novel regulatory mechanisms in Saccharomyces cerevisiae. Genome Res 2006, 16(5):627-635.

22. Kuepfer L, Sauer U, Blank LM: Metabolic functions of duplicate genes in Saccharomyces cerevisiae. Genome Res 2005, 15(10): $1421-1430$.

23. Blank LM, Kuepfer L, Sauer U: Large-scale I3C-flux analysis reveals mechanistic principles of metabolic network robustness to null mutations in yeast. Genome Biol 2005, 6(6):R49.

24. Han G, Gable K, Kohlwein SD, Beaudoin F, Napier JA, Dunn TM: The Saccharomyces cerevisiae YBRI59w gene encodes the 3ketoreductase of the microsomal fatty acid elongase. J Biol Chem 2002, 277(38):35440-35449.

25. Alvarez-Vasquez F, Sims KJ, Cowart LA, Okamoto Y, Voit EO, Hannun YA: Simulation and validation of modelled sphingolipid metabolism in Saccharomyces cerevisiae. Nature 2005, 433(7024):425-430.

26. Welch JW, Burlingame AL: Very long-chain fatty acids in yeast. J Bacteriol 1973, I I5(I):464-466.

27. Schulze U: Anaerobic physiology of Saccharomyces cerevisiae. Lyngby, Technical University of Denmark; 1995.

28. Dyer JM, Chapital DC, Kuan JW, Mullen RT, Pepperman AB: Metabolic engineering of Saccharomyces cerevisiae for production of novel lipid compounds. Appl Microbiol Biotechnol 2002, 59(23):224-230.

29. Jollow D, Kellerman GM, Linnane AW: The biogenesis of mitochondria. 3. The lipid composition of aerobically and anaerobically grown Saccharomyces cerevisiae as related to the membrane systems of the cells. / Cell Biol I968, 37(2):22I-230.

30. Edwards JS, Ibarra RU, Palsson BO: In silico predictions of Escherichia coli metabolic capabilities are consistent with experimental data. Nat Biotechnol 200I, 19(2):125-130.

31. Feist AM, Henry CS, Reed JL, Krummenacker M, Joyce AR, Karp PD, Broadbelt LI, Hatzimanikatis V, Palsson BO: A genome-scale metabolic reconstruction for Escherichia coli K-I 2 MGI655 that accounts for 1260 ORFs and thermodynamic information. Mol Syst Biol 2007, 3:121.

32. Reed JL, Vo TD, Schilling CH, Palsson BO: An expanded genomescale model of Escherichia coli K-I2 (iJR904 GSM/GPR). Genome Biol 2003, 4(9):R54.

33. Gombert AK, Moreira dos Santos M, Christensen B, Nielsen J: Network identification and flux quantification in the central metabolism of Saccharomyces cerevisiae under different conditions of glucose repression. J Bacteriol 200I, I 83(4): I44I-I I 5 I.

34. Winzeler EA, Shoemaker DD, Astromoff A, Liang H, Anderson K, Andre B, Bangham R, Benito R, Boeke JD, Bussey H, Chu AM, Connelly C, Davis K, Dietrich F, Dow SW, El Bakkoury M, Foury F, Friend SH, Gentalen E, Giaever G, Hegemann JH, Jones T, Laub M, Liao H, Liebundguth N, Lockhart DJ, Lucau-Danila A, Lussier M, M'Rabet N, 
Menard P, Mittmann M, Pai C, Rebischung C, Revuelta JL, Riles L, Roberts CJ, Ross-MacDonald P, Scherens B, Snyder M, Sookhai-Mahadeo $S$, Storms RK, Veronneau S, Voet M, Volckaert G, Ward TR, Wysocki R, Yen GS, Yu K, Zimmermann K, Philippsen P, Johnston M, Davis RW: Functional characterization of the $S$. cerevisiae genome by gene deletion and parallel analysis. Science 1999, 285(5429):90I-906.

35. Tu BP, Kudlicki A, Rowicka M, McKnight SL: Logic of the yeast metabolic cycle: temporal compartmentalization of cellular processes. Science 2005, 3 I0(575I): II52-II58.

36. Tai SL, Boer VM, Daran-Lapujade P, Walsh MC, de Winde JH, Daran JM, Pronk JT: Two-dimensional transcriptome analysis in chemostat cultures. Combinatorial effects of oxygen availability and macronutrient limitation in Saccharomyces cerevisiae. J Biol Chem 2005, 280(I):437-447.

37. Pizarro F, Jewett MC, Nielsen J, Agosin E: Physiological and transcriptional mapping of evolutionary differences between laboratory and commercial Saccharomyces cerevisiae strains(submitted). 2008.

38. Kolkman A, Daran-Lapujade P, Fullaondo A, Olsthoorn MM, Pronk JT, Slijper $M$, Heck AJ: Proteome analysis of yeast response to various nutrient limitations. Mol Syst Biol 2006, 2:2006 0026.

39. Gurvitz A, Mursula AM, Firzinger A, Hamilton B, Kilpelainen SH, Hartig A, Ruis H, Hiltunen JK, Rottensteiner H: Peroxisomal Delta3cis-Delta2-trans-enoyl-CoA isomerase encoded by ECII is required for growth of the yeast Saccharomyces cerevisiae on unsaturated fatty acids. J Biol Chem 1998, 273(47):3I366-3I374.

40. Rodriguez-Vargas S, Sanchez-Garcia A, Martinez-Rivas JM, Prieto JA, Randez-Gil F: Fluidization of membrane lipids enhances the tolerance of Saccharomyces cerevisiae to freezing and salt stress. Appl Environ Microbiol 2007, 73(I): I I0-I I6.

4I. Hirschman JE, Balakrishnan R, Christie KR, Costanzo MC, Dwight SS, Engel SR, Fisk DG, Hong EL, Livstone MS, Nash R, Park J, Oughtred R, Skrzypek M, Starr B, Theesfeld CL, Williams J, Andrada R, Binkley G, Dong Q, Lane C, Miyasato S, Sethuraman A, Schroeder M, Thanawala MK, Weng S, Dolinski K, Botstein D, Cherry JM: Genome Snapshot: a new resource at the Saccharomyces Genome Database (SGD) presenting an overview of the Saccharomyces cerevisiae genome. Nucleic Acids Res 2006, 34(Database issue):D442-5.

42. Guldener U, Munsterkotter M, Kastenmuller G, Strack N, van Helden J, Lemer C, Richelles J, Wodak SJ, Garcia-Martinez J, Perez-Ortin JE, Michael H, Kaps A, Talla E, Dujon B, Andre B, Souciet JL, De Montigny J, Bon E, Gaillardin C, Mewes HW: CYGD: the Comprehensive Yeast Genome Database. Nucleic Acids Res 2005, 33(Database issue):D364-8.

43. Csank C, Costanzo MC, Hirschman J, Hodges P, Kranz JE, Mangan M, O'Neill K, Robertson LS, Skrzypek MS, Brooks J, Garrels Jl: Three yeast proteome databases: YPD, PombePD, and CalPD (MycoPathPD). Methods Enzymol 2002, 350:347-373.

44. Arakawa K, Kono N, Yamada Y, Mori H, Tomita M: KEGG-based pathway visualization tool for complex omics data. In Silico Biol 2005, 5(4):419-423.

45. Gasteiger E, Gattiker A, Hoogland C, Ivanyi I, Appel RD, Bairoch A ExPASy: The proteomics server for in-depth protein knowledge and analysis. Nucleic Acids Res 2003, 3 I (I 3):3784-3788.

46. Vastrik I, D'Eustachio P, Schmidt E, Joshi-Tope G, Gopinath G, Croft D, de Bono B, Gillespie M, Jassal B, Lewis S, Matthews L, Wu G, Birney $E$, Stein L: Reactome: a knowledge base of biologic pathways and processes. Genome Biol 2007, 8(3):R39.

47. Edwards JS, Palsson BO: The Escherichia coli MG 1655 in silico metabolic genotype: its definition, characteristics, and capabilities. Proc Natl Acad Sci U S A 2000, 97( 1 0):5528-5533.

48. Vaughan-Martini A, Martini A, Cardinali G: Electrophoretic karyotyping as a taxonomic tool in the genus Saccharomyces. Antonie Van Leeuwenhoek 1993, 63(2): 145-156.

49. Barrett T, Edgar R: Gene expression omnibus: microarray data storage, submission, retrieval, and analysis. Methods Enzymol 2006, 4 II:352-369.

50. Schadt EE, Li C, Ellis B, Wong WH: Feature extraction and normalization algorithms for high-density oligonucleotide gene expression array data. J Cell Biochem Suppl 200I, Suppl 37: $120-125$.

5I. Harbison CT, Gordon DB, Lee TI, Rinaldi NJ, Macisaac KD, Danford TW, Hannett NM, Tagne JB, Reynolds DB, Yoo J, Jennings EG, Zeitlinger J, Pokholok DK, Kellis M, Rolfe PA, Takusagawa KT, Lander ES,
Gifford DK, Fraenkel E, Young RA: Transcriptional regulatory code of a eukaryotic genome. Nature 2004, 43 I (7004):99- 104.

52. Stark C, Breitkreutz BJ, Reguly T, Boucher L, Breitkreutz A, Tyers M: BioGRID: a general repository for interaction datasets. Nucleic Acids Res 2006, 34(Database issue):D535-9.

53. Ideker TE, Thorsson V, Karp RM: Discovery of regulatory interactions through perturbation: inference and experimental design. Pac Symp Biocomput 2000:305-316.

54. Shannon P, Markiel A, Ozier O, Baliga NS, Wang JT, Ramage D, Amin $\mathrm{N}$, Schwikowski B, Ideker T: Cytoscape: a software environment for integrated models of biomolecular interaction networks. Genome Res 2003, I3( I I):2498-2504.
Publish with Biomed Central and every scientist can read your work free of charge

"BioMed Central will be the most significant development for disseminating the results of biomedical research in our lifetime. "

Sir Paul Nurse, Cancer Research UK

Your research papers will be:

- available free of charge to the entire biomedical community

- peer reviewed and published immediately upon acceptance

- cited in PubMed and archived on PubMed Central

- yours - you keep the copyright

Submit your manuscript here:

http://www.biomedcentral.com/info/publishing_adv.asp 